Article

\title{
Proteinuria and Bilirubinuria as Potential Risk Indicators of Acute Kidney Injury during Running in Outpatient Settings
}

\author{
Daniel Rojas-Valverde ${ }^{1,2, *(\mathbb{0})}$, Guillermo Olcina ${ }^{2, *} \mathbb{C}$, Braulio Sánchez-Ureña ${ }^{3}{ }^{(0)}$, \\ José Pino-Ortega ${ }^{4}$ (D) Ismael Martínez-Guardado ${ }^{2}$ and Rafael Timón ${ }^{2, *(D)}$ \\ 1 Centro de Investigación y Diagnóstico en Salud y Deporte (CIDISAD), Escuela Ciencias del Movimiento \\ Humano y Calidad de Vida (CIEMHCAVI), Universidad Nacional, Heredia 86-3000, Costa Rica \\ 2 Grupo en Avances en el Entrenamiento Deportivo y Acondicionamiento Físico (GAEDAF), \\ Facultad Ciencias del Deporte, Universidad de Extremadura, 10005 Cáceres, Spain; wismu04@gmail.com \\ 3 Programa Ciencias del Ejercicio y la Salud (PROCESA), Escuela Ciencias del Movimiento Humano y Calidad \\ de Vida (CIEMHCAVI), Universidad Nacional, Heredia 86-3000, Costa Rica; brau09@hotmail.com \\ 4 Departmento de Actividad Física y Deporte, Facultad Ciencias del Deporte, 30720 Murcia, Spain; \\ josepinoortega@um.es \\ * Correspondence: drojasv@una.cr (D.R.-V.); golcina@unex.es (G.O.); rtimon@unex.es (R.T.); \\ Tel.: +506-8825-0219 (D.R.-V.)
}

Received: 2 September 2020; Accepted: 19 October 2020; Published: 27 October 2020

check for updates

\begin{abstract}
Background and objectives: The purpose of this study was to explore which urinary markers could indicate acute kidney injury (AKI) during prolonged trail running in outpatient settings. Materials and Methods: Twenty-nine experienced trail runners (age $39.1 \pm 8.8$ years, weight $71.9 \pm 11 \mathrm{~kg}$, height $171.9 \pm 8.3 \mathrm{~cm}$ ) completed a $35 \mathrm{~km}$ event (cumulative positive ascend of $1815 \mathrm{~m}$, altitude $=906$ to 1178 m.a.s.l.) under a temperature of $25.52 \pm 1.98^{\circ} \mathrm{C}$ and humidity of $79.25 \pm 7.45 \%$ ). Two participant groups (AKI $=17$ and No-AKI $=12$ ) were made according to AKI diagnosis criteria based on preand post-race values of serum creatinine ( $\mathrm{sCr}$ ) (an increase of 1.5 times from baseline). Blood and urinalysis were performed immediately pre- and post-race. Results: Pre- vs. post-race differences in $\mathrm{sCr}$ and sBUN were found in both AKI and No-AKI groups $(p<0.01)$. Differences in post-race values were found between groups $(p=0.03)$. A total of $52 \%$ of AKI runners presented significant increases in proteinuria $\left(\chi^{2}=0.94, p=0.01\right)$ and $47 \%$ in bilirubinuria $\left(\chi^{2}=0.94, p=0.04\right)$. Conversely, No-AKI participants presented no significant increases in urine markers. Conclusions: These study's findings may suggest the potential use of urinalysis as an accessible alternative in the outpatient setting to early identify transitional AKI until a clinical confirmation is performed.
\end{abstract}

Keywords: urine; biomarkers; renal health; assessment; mountain running; acute renal failure

\section{Introduction}

Acute kidney injury (AKI) is a condition defined as an injury or damage accompanied in some cases by renal dysfunction over a relatively short period [1-3]. This takes into account that human kidneys have a significant glomerular function reserve and dysfunction may be evident only when more than $50 \%$ of the total renal mass is compromised [4]. This sudden episode of kidney damage occurs within a few hours $(<48 \mathrm{~h})$, causing a build-up of waste products in the bloodstream, making it difficult for kidneys to maintain the body's fluid balance. This abrupt kidney damage occurs in a wide range of clinical settings. It represents a relatively common but under-recognized problem in sports medicine and science, and AKI's long-term effects on renal function are still unclear [5]. 
Transitional AKI has been reported as a severe condition with an increasing incidence in endurance sports such as triathlon, open water, swimming, cycling, and running. Approximately $16 \%$ to $50 \%$ of athletes participating in long-distance events fulfill AKI diagnosis criteria [5], and 97\% of these participants are endurance runners [5]. Muscle damage and subsequent inflammatory responses could result from consecutive eccentric-concentric muscle contraction during endurance running and be AKI's potential cause [5-8]. In strenuous and prolonged events, AKI etiology is considered multifactorial, and heat strain, dehydration, high metabolic, and physical load are potential enhancers of this temporal decrease in kidney function $[5,9,10]$.

Some evidence has reported that blood markers' changes seem to be a physiological reaction in sports, and it is overestimated in AKI [11]. Recent epidemiological and experimental studies have demonstrated a real link between AKI and chronic kidney disease (CKD) [12,13]. Repeated AKI episodes, even mild cases, may induce CKD over the long term. The potential link between consecutive AKI episodes and CKD has to be confirmed in sports due to the need for clarification around nature and precise mechanisms leading to AKI in these activities. It is known that prolonged exercising does not impact short-term kidney function, and it is transitional damage that usually requires a few days to recover normal function $[5,14]$.

AKI is usually assessed using markers such as serum creatinine ( $\mathrm{sCr}$ ), albumin, serum blood ureic nitrogen (sBUN), cystatin-C, neutrophil gelatinase-associated lipocalin (NGAL), kidney injury molecule-1 (KIM-1), pro-inflammatory cytokines (e.g., IL-18), and liver-type fatty acid-binding protein [15-18]. This condition is also defined, classified, and stratified based on severity according to some classification systems, such as Risk, Injury, Failure, Loss, and End-Stage (RIFLE) and Acute Kidney Injury Network (AKIN) criteria [3,19]. This diagnosis criterion allows earlier identification of AKI and diagnosis, even in the absence of subsequent kidney dysfunction $[4,20]$.

AKI is also associated with urine alterations [21], such as the high prevalence of proteinuria [11], hematuria [22], albuminuria [23], and creatinuria [24] with a return to baseline after a few days. Urine analysis is usually performed using urine samples analyzed in the laboratory, but urine dipstick readings are generally used as an accessible alternative $[25,26]$. In endurance sports, it has been shown that long races, compared to short races, present a higher incidence of urine alterations [11], so it is related to duration but not intensity [27]. These changes in urine characteristics are usually associated with hemodynamic adjustments as hemoconcentration and renal hypoperfusion due to dehydration during endurance sports [23].

The increase in wide-spread participation in endurance events has raised concerns around these activities' potential implications for the participant's kidney health $[4,10]$. Considering that adverse environmental conditions such as high temperature and humidity as in tropical settings increase AKI's risk, renal function must be monitored in endurance sports such as running, mostly when it is practiced in hot regions [28,29]. Additionally, it is fundamental to have more available options to monitor kidney function during training and competition. Based on previous evidence, urinalysis could be an alternative and accessible method to identify AKI early in the field. These measurements could offer some vital information to allow action to be taken on affected athletes in the field, while waiting for subsequent confirmation analysis (e.g., medical imaging or blood tests). This kind of in-field analysis could provide objective data to boost prevention strategies in those diagnosed participants. Since AKI can be highlighted as a severe clinical problem with significant morbidity, the objective of this study was to explore which urinary markers could indicate AKI during prolonged trail running in outpatient settings.

\section{Materials and Methods}

\subsection{Design}

This was a retrospective cohort study where participants completed a $35 \mathrm{~km}$ event (cumulative positive ascend of $1815 \mathrm{~m}$, altitude $=906$ to 1178 m.a.s.l.). The event was held in Mora, San José, Costa 
Rica under a temperature of $25.52 \pm 1.98^{\circ} \mathrm{C}$ and humidity of $79.25 \pm 7.45 \%$ (QUESTemp ${ }^{\mathrm{TM}} 36,3 \mathrm{M}$, Saint Paul, MN, USA). Two participant groups (AKI = 17 and No-AKI = 12) were made according to AKI risk criteria based on pre- and post-race values of $\mathrm{sCr}$ (an increase of 1.5 times from baseline) [19]. Both blood and urinalysis were performed immediately pre- and post-race. Serum and urine samples were collected $\sim 15 \mathrm{~min}$ before and $\sim 15 \mathrm{~min}$ after the race (see Figure 1). Participant's finish time was $4.5 \pm 0.3 \mathrm{~h}$.

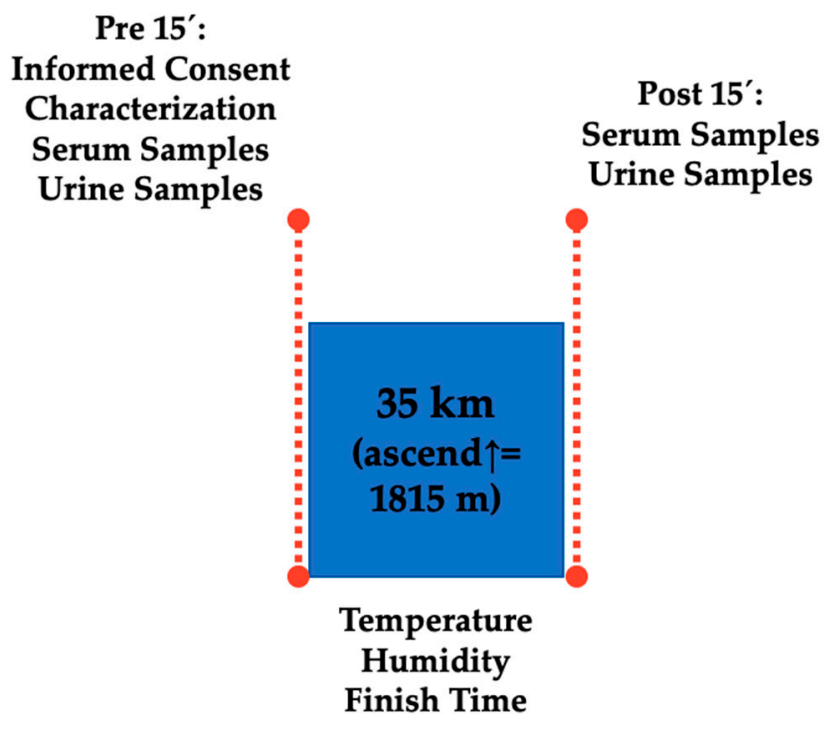

Figure 1. Schematic design of study assessments.

\subsection{Participants}

Twenty-nine mountain runners (age $39 \pm 9.1$ years, weight $71.7 \pm 10.8 \mathrm{~kg}$, height $172.2 \pm 8.3 \mathrm{~cm}$ ) took part in the study. Participants were selected among $>18$ years old, voluntary, experienced (5.41 \pm 2.79 years), trained $(8.8 \pm 3.4 \mathrm{~h} /$ week), and heat acclimatized (sleep and train in similar study's altitude and weather) ultra-endurance runners. Participants were recruited from a single endurance event and reported no neuromuscular injuries or metabolic disturbances at least six months before the race.

The experimental protocol was approved by the Institutional Review Board of Universidad Nacional de Costa Rica (Reg. Code UNA-CECUNA-2019-P005; 17 June 2019) and Universidad de Extremadura (Reg. Code 139/2020; 25 September 2020). All participants were informed of the details of the experimental procedures and the associated risks and discomforts, as well as their benefits and rights. According to the criteria of the Declaration of Helsinki, each participant gave written informed consent regarding biomedical research involving human subjects (18th Medical Assembly, 1964, revised in 2013 in Fortaleza).

\subsection{Materials and Procedures}

\subsubsection{Serum Test}

Blood was extracted in situ from the antecubital vein using a $5 \mathrm{~mL}$ blood collection sterile tube (Vacutainer ${ }^{\mathrm{TM}}$, Becton, Dickinson \& Company, Franklin Lakes, NJ, USA) containing a spray-coated silica particle activator. Tubes contained a gel polymer to facilitate serum separation during centrifugation (10 min at 2000 $\times g$ relative centrifugal force) using centrifuge tubes (PLC-01, Gemmy Industrial Corp., Taipei, Taiwan). Blood samples were stored on ice in a special cooler (45QW Elite, Pelican Products $^{\mathrm{TM}}$, Torrance, CA, USA) until serum samples were frozen at $-20{ }^{\circ} \mathrm{C}(\sim 5 \mathrm{~h}$ after blood extraction). Sample analysis and processing were performed $24 \mathrm{~h}$ after data collection in an isolated 
and temperature-controlled laboratory using an automatic biochemical analyzer (BS-200E, Mindray, city, China) by photometry method. All procedures were performed under relevant protocols for the handling and disposal of biological materials, according to the manufacturer's instructions for the equipment and reagents used. The analyzed variables were $\mathrm{sCr}(\mathrm{mg} / \mathrm{dL})$ and $\mathrm{sBUN}(\mathrm{mg} / \mathrm{dL})$.

\subsubsection{Urine Test}

Urine samples were collected in situ in a $30 \mathrm{~mL}$ polypropylene sterile urine sample container (Nipro Medical Corp., Osaka, Japan). Samples were analyzed using highly sensitive and accurate dipsticks for urine screening (Combur ${ }_{10}$ Test M, Roche, Mannheim, Germany) during distance running [25]. Urine dipsticks were examined immediately after collection by two different microbiologists simultaneously using the manufacturer's color scale. In case of disagreement between observers, a consensus was obtained by the opinion of a third researcher. The following parameters were screened: leucocytes, erythrocytes, bilirubin, ketones, nitrites, protein, glucose, and urobilinogen. There were no reported urination problems or difficulties neither before nor after the race. Traces were considered as negatives, and those scores $>1$ were reported. Urine test interpretation and reporting were made as follows: $>1$ score was equivalent to leucocytes $>10$ cells $/ \mu \mathrm{L}$, erythrocytes $>5$ cells $/ \mu \mathrm{L}$, bilirubin $>1$, ketones $>1$, nitrites + , protein $>30 \mathrm{mg} / \mathrm{dL}$, glucose $>50 \mathrm{mg} / \mathrm{dL}$, and urobilinogen $>1 \mathrm{mg} / \mathrm{dL}$.

\subsubsection{Urine Specific Gravity}

Urine specific gravity (USG) was assessed as a hydration status marker. Urine solids were assessed, and USG was confirmed and double-checked with a digital valid [30] handheld refractometer (Palm Abbe ${ }^{\mathrm{TM}}$, Misco, Solon, OH, USA). It was classified following the hydration status ranges: well-hydrated $<1.01$, minimal dehydration 1.01-1.02, significant dehydration 1.02-1.03, and severe dehydration $>1.03$ [31]. The refractometer was cleaned with distilled water and calibrated previously.

\subsection{Statistical Analysis}

The description of variables was reported using mean, standard deviation, and lower and upper limits. The normality of the data was confirmed using the Shapiro-Wilk test. Participants' basic data and characteristics were compared using an independent $t$-test. Differences between AKI and No-AKI groups in blood biomarkers and USG were explored using a mixed analysis of variance, and post-hoc of Bonferroni was performed to look after specific differences. Omega squared $\left(\omega_{\mathrm{p}}{ }^{2}\right)$ was selected to qualify the magnitude of the differences as follows: $<0.01$ trivial; $>0.01$ small; $>0.06$ moderate, and $>0.14$ large [32].

McNemar's non-parametric test was used to explore the possible change in proportion for the paired data of urinalysis. In those observed cases, the intersection frequency value was $<5$; the binomial test was performed. The data of urinalysis were paired by measurement moment using a $2 \times 2$ contingency table. Alpha was set at $p<0.05$, and all data were analyzed and systematized using the e Statistical Package for the Social Sciences (SPSS, IBM, SPSS Statistics, v.22.0, Chicago, IL, USA).

\section{Results}

Table 1 shows the comparison between AKI and No-AKI groups based on the participants' basic data and characteristics. There were no differences in this participant's information by group. 
Table 1. Participants' basic data and characteristics comparison.

\begin{tabular}{ccccc}
\hline & AKI & No-AKI & $\boldsymbol{t}$ & $\boldsymbol{p}$-Value \\
\hline Age (years) & $39.4 \pm 8.8$ & $38.1 \pm 9.8$ & 0.34 & 0.74 \\
Weight (kg) & $69.2 \pm 7.3$ & $76 \pm 14.5$ & -0.99 & 0.33 \\
Height (cm) & $171.6 \pm 7.6$ & $173.1 \pm 9.6$ & 0.41 & 0.69 \\
Trail running experience (years) & $5 \pm 2.6$ & $6.1 \pm 3.1$ & -1.63 & 0.12 \\
Training (hours) & $9.1 \pm 2.8$ & $8.5 \pm 4.5$ & -0.45 & 0.66 \\
\hline
\end{tabular}

There were 17 participants that met AKI criteria ( $\mathrm{sCr}=1.18 \pm 0.26$ pre, $1.81 \pm 0.35$ post, change of $53.4 \%$ ). There were large differences by measurement (pre vs. post) and group (AKI vs. No-AKI) in $\mathrm{sCr}\left(\mathrm{F}=17.24, p<0.01, \omega_{\mathrm{p}}{ }^{2}=0.38\right.$ (large)) and sBUN $\left(\mathrm{F}=4.1, p<0.5, \omega_{\mathrm{p}}{ }^{2}=0.1\right.$ (large)). Pre vs. post differences were found in both AKI $(p<0.01)$ and No-AKI $(p<0.01)$ groups in sCr and sBUN. Moreover, in $\mathrm{sCr}$ values, post-race differences between AKI and No-AKI groups were found ( $p=0.03)$ but no pre-race differences were identified $(p=0.34)$ (see Figure 2a). Additionally, in sBUN values, there were no pre- or post-race differences between AKI and No-AKI groups (see Figure 2b).
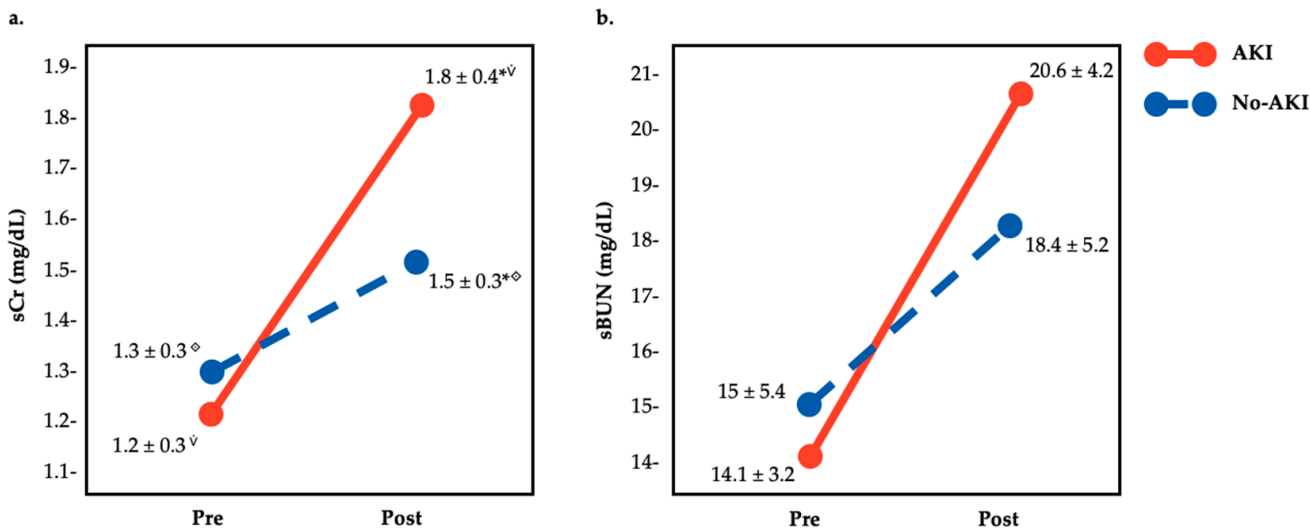

Figure 2. Comparison of pre- and post-race (a). serum creatinine ( $\mathrm{sCr}$ ), and (b). serum blood ureic nitrogen (sBUN) values of trail runners by the presence or not of acute kidney injury. $\dot{v}^{*}$ significant statistical differences.

Of AKI runners, 52.94\% presented a significant increase in proteinuria $\left(\chi^{2}=0.94, p=0.01\right)$ and $47.06 \%$ in bilirubinuria $\left(\chi^{2}=0.94, p=0.04\right)$ when comparing pre- vs. post-race values. No significant increases were found in leucocyturia $\left(17.64 \%, \chi^{2}=04.96, p=0.5\right)$, urobilonogenuria $\left(17.64 \%, \chi^{2}=0.23\right.$, $p=0.63)$, and hematuria $\left(29.41 \%, \chi^{2}=0.58, p=0.13\right)$. No cases of nitrituria, glucosuria, or ketonuria were found (see Table 2).

Table 2. Urinalysis outcomes in participants fulfilling acute kidney injury (AKI) diagnosis criteria.

\begin{tabular}{ccccccc}
\hline \multirow{2}{*}{$\begin{array}{c}\text { Variable } \\
\text { (Score Criteria) }\end{array}$} & \multicolumn{2}{c}{ Pre } & \multicolumn{2}{c}{ Post 0 h } & \multirow{2}{*}{$\boldsymbol{\chi}^{\mathbf{2}}$} & $\boldsymbol{p}$-Value \\
\cline { 2 - 5 } & $\boldsymbol{n}^{*}$ & $\mathbf{\%}$ & $\boldsymbol{n}^{*}$ & $\mathbf{\%}$ & & \\
\hline Leucocytes $(>1)$ & 0 & 0 & 3 & 17.64 & 4.96 & 0.5 \\
Nitrites $(>1)$ & 0 & 0 & 0 & 0 & - & - \\
Protein $(>1)$ & 0 & 0 & 9 & 52.94 & 0.94 & 0.008 \\
Glucose $(>1)$ & 0 & 0 & 0 & 0 & - & - \\
Ketones $(>1)$ & 0 & 0 & 0 & 0 & - & - \\
Urobilinogen $(>1)$ & 0 & 0 & 3 & 17.64 & 0.23 & 0.625 \\
Bilirubin $(>1)$ & 0 & 0 & 8 & 47.06 & 0.94 & 0.039 \\
Erythrocytes $(>1)$ & 0 & 0 & 5 & 29.41 & 0.58 & 0.125 \\
\hline
\end{tabular}


Furthermore, 12 participants did not develop AKI ( $\mathrm{SCr}=1.28 \pm 0.28$ pre, $1.5 \pm 0.3$ post). Proteinuria $\left(33.33 \%, \chi^{2}=1.67, p=0.25\right)$, ketonuria $\left(16.66 \%, \chi^{2}=0.28, p=1\right)$, bilirubinuria $(41.66 \%$, $\left.\chi^{2}=0.74, p=0.63\right)$, urobilonogenuria $\left(8.33 \%, \chi^{2}=0.12, p=1\right)$, and hematuria $\left(33.33 \%, \chi^{2}=2.59, p=0.5\right)$ were found but with no significant change. No cases of leucocyturia, nitrituria, or glucosuria were presented in the No-AKI group (see Table 3).

Table 3. Urinalysis outcomes in participants without AKI diagnosis.

\begin{tabular}{ccccccc}
\hline \multirow{2}{*}{$\begin{array}{c}\text { Variable } \\
\text { (Score Criteria) }\end{array}$} & \multicolumn{2}{c}{ Pre } & \multicolumn{2}{c}{ Post 0 h } & \multirow{2}{*}{$\boldsymbol{x}^{\mathbf{2}}$} & $\boldsymbol{p}$-Value \\
\cline { 2 - 5 } & $\boldsymbol{n}^{*}$ & $\%$ & $\boldsymbol{n}^{*}$ & $\%$ & & \\
\hline Leucocytes $(>1)$ & 0 & 0 & 0 & 0 & - & - \\
Nitrites $(>1)$ & 0 & 0 & 0 & 0 & - & - \\
Protein $(>1)$ & 0 & 0 & 4 & 33.33 & 1.667 & 0.25 \\
Glucose $(>1)$ & 0 & 0 & 0 & 0 & - & - \\
Ketones $(>1)$ & 0 & 0 & 2 & 16.66 & 0.278 & 1 \\
Urobilinogen $(>1)$ & 0 & 0 & 1 & 8.33 & 0.123 & 1 \\
Bilirubin $(>1)$ & 0 & 0 & 5 & 41.66 & 0.741 & 0.063 \\
Erythrocytes $(>1)$ & 0 & 0 & 3 & 33.33 & 2.59 & 0.5 \\
\hline & * Based on No-AKI group data $(n=12)$. & &
\end{tabular}

Finally, USG as a hydration marker showed no significant interaction in AKI vs. No-AKI groups $\left(\mathrm{F}=0.62, p=0.44, \omega_{\mathrm{p}}^{2}=0\right.$ (trivial) $)$. There were no pre vs. post differences $(\mathrm{F}=3.1, p=0.09 ;$ pre $=1.018$ vs. post $=1.023)$.

\section{Discussion}

This study aimed to explore which urinary markers could indicate AKI during prolonged trail running in outpatient settings. The main findings of this study were as follows: (1) Pre- vs. post-race differences in $\mathrm{sCr}$ and sBUN were found in both AKI and No-AKI groups $(p<0.01)$; (2) differences in post-race values were found between groups $(p=0.03)$; (3) a total of $52 \%$ of AKI runners presented significant increases in proteinuria $\left(\chi^{2}=0.94, p=0.01\right)$ and $47 \%$ in bilirubinuria $\left(\chi^{2}=0.94, p=0.04\right)$; and, conversely, (4) No-AKI participants presented no significant increases in urine markers.

AKI could be caused by a series of factors such as decreased blood flow, direct kidney trauma, blockage of the urinary tract, among others [33]. In sports, precisely in endurance sports, the mechanisms are still unclear. Some factors such as heat strain, dehydration, and high metabolic and physical load may boost the risk and are primary issues. Dehydration seems to be a factor that did not influence the AKI occurrence in this specific sample, as found in the results. In strenuous exercise, high physical load during prolonged periods has an essential role in AKI development [6,34]. The relative typical rise in $\mathrm{sCr}$ values during endurance events could suggest a high muscle damage rate due to the release of sarcoplasmic proteins into the bloodstream. Damage and disintegration of muscle fibers are expected consequences of strenuous physical exertion. Distance running events are one of the most physically demanding sports, and the subsequent structural and functional damage could be exacerbated due to the repetitive concentric-eccentric muscle actions when running uphill and downhill as happen in endurance trail training and competitions. These efforts usually require greater impact absorption and a higher metabolic rate $[6,35,36]$ as compared to other sports.

Protein is one of the main structural components of muscle fibers in the body. Under normal conditions, the kidney's protein excreted in healthy adults is about 150mg per day [37]. As a consequence of muscle damage, an excess of proteins is excreted through the urine, and a condition known as proteinuria could develop. This condition is asymptomatic and associated with intense exercise, also called exercise-induced proteinuria [22], as was found in the present study.

The pathophysiological mechanisms of proteinuria can be partially explained by increasing glomerular capillary permeability to proteins and reduced protein reabsorption capacity in the 
renal tubules. Still, exercise-induced proteinuria is not fully understood, but it seems that the renin-angiotensin system and prostaglandins have an essential role in its development [38].

Proteinuria and bilirubinuria in endurance sports could be a consequence of a cascade of events in the kidney. In non-contact sports, catecholamines are released by the suprarenal glandules causing a redirection of blood to muscles and restricting kidney blood flow. These events lead to hypoxic nephron damage and an increase in glomerular permeability [39]. Vasoconstriction of the glomerular arteriole is also provoked by catecholamines, resulting in decreased glomerular filtration pressure and allowing excretion of some macro- and microscopic elements in urine as protein, erythrocytes, albumin, and bilirubin. Other factors contributing to exercise proteinuria could be, but are not limited to, lactate accumulation, oxidant stress, hormonal changes, and sepsis [22,25].

The increase in bilirubin found in this research could be caused by hemolysis and subsequent catabolism of hemoglobin. The proliferation of red blood cell breakdown is caused mainly by free radicals and a mechanical factor [40]. Bilirubinuria could also be related to hepatic disturbance during long-distance running [41,42]. Endurance running may cause a decline in hepatic function related to changes in the liver cells' membrane by lipid peroxidation due to blood flow restrictions and free radicals' release. It is known that the liver suffers a temporary decline in its function during prolonged exercises compared to running over shorter distances [42]. A condition called foot-strike hemolysis suggests that blood cells' mechanical injury could be related to the consecutive impact during running [43].

Exercise-related proteinuria and bilirubinuria have been related to renal and hepatic dysfunctions. Both conditions could be asymptomatic, transitional, reversible, and, usually, they do not need any special care. However, endurance athletes could be particularly vulnerable to developing such conditions when exposing themselves to a high level of environmental stress, such as a hot and humid environment $[10,44,45]$. These conditions could boost ischemia, hypoxemia, and ATP depletion in renal tubular cells, and considering dehydration, it could be exacerbated by increased sodium reabsorption [29].

The presence of AKI cases with concomitant proteinuria and bilirubinuria may suggest the potential use of urinalysis as an accessible alternative to identify AKI cases early in the field and monitor training and competition as an outpatient setting. The screening of urine changes could represent an opportunity to identify the potential risk of AKI cases in a simple and fast manner. This result must be analyzed with caution, considering that only 47 to $52 \%$ of AKI runners presented urine changes.

Based on quantitative results, scientists could overlook the incidence and prevalence of AKI cases with concomitant urine findings. Still, at the clinical level, these results' potential implications may lead stakeholders to deeply analyze those cases, although it could be considered relatively uncommon [5]. Finally, there is no clear link between AKI and more severe complications such as chronic kidney disease in endurance sports. Some actions must be addressed to prevent future health issues in athletes. Managing fluid intake and restoring electrolytes prior to, during, and after endurance events may contribute to the reduction of the number or lessen the severity of AKI cases. Avoiding repeated participation at endurance events without the required rest and recovery between exhaustive efforts could be protective against AKI.

These findings must be seen in the light of some limitations. Some contextual factors such as liquid intake, food consumption, and supplements during running should be controlled in future studies. Despite limited access, it may be interesting to assess some novel AKI indicators as Cyst-C, NGAL, and KIM-1 as subclinical AKI markers. It is fundamental to develop a cohort follow-up to confirm the potentiality of cumulative AKI events leading to CKD. Unfortunately, assessing blood and urine samples of a large cohort for research purposes during a long-distance event as trail running is not always feasible; future studies must include a greater sample size.

Homogeneity between groups and diagnosis criteria of AKI made it difficult to interpret why there were no differences between AKI vs. No-AKI groups, considering there was an occurrence 
of proteinuria in 33\% of No-AKI cases as well as differences in sCr and sBUN between pre- and post-race assessments. This may suggest that, during clinical evaluation of AKI during endurance sports, patients may be analyzed individually to explore these findings' real relevance and potential runner's health impairment.

Additionally, it should be considered that dipstick analysis is usually used in most outpatient settings to semi-quantitatively measure the urine protein concentration but not the type or total amount. These tests are a crude estimation of urine protein concentration, so this is an initial approach for AKI that seems to correlate with AKI markers. Runners with persistent proteinuria should undergo a quantitative measurement of protein excretion using, for example, a 24-h urine specimen (urine protein/Cr).

\section{Conclusions}

Endurance trail running could lead to an increase in some blood and urine samples related to transitory AKI. This study found pre- vs. post-race differences in sCr and sBUN in both AKI and No-AKI groups, differences in post-race values between groups ( $p=0.03$ ), and a total of $52 \%$ of AKI runners presented significant increases in proteinuria $\left(\chi^{2}=0.94, p=0.01\right)$ and $47 \%$ in bilirubinuria $\left(\chi^{2}=0.94, p=0.04\right)$.

These results may suggest that AKI prevalence with concomitant proteinuria and bilirubinuria is relatively uncommon among endurance runners. Although these cases do not represent most of the runner's condition, at clinical level care, these findings must be taken with precaution to prevent future complications. Furthermore, although there is insufficient evidence that links AKI to other future complications, these markers should be monitored during training and competition to prevent potential future damage.

Author Contributions: Conceptualization, D.R.-V.; methodology, D.R.-V., G.O., B.S.-U. and R.T.; software, D.R.-V. and J.P.-O.; validation, D.R.-V., G.O., B.S.-U. and R.T.; formal analysis, D.R.-V.; investigation, D.R.-V., B.S.-U., and J.P.-O.; resources, D.R.-V. and B.S.-U.; data curation, D.R.-V., J.P.-O. and I.M.-G.; writing-original draft preparation, D.R.-V. and I.M.-G.; writing—review and editing, D.R.-V., G.O., B.S.-U. and R.T.; supervision, D.R.-V., G.O., B.S.-U. and R.T.; project administration, D.R.-V., G.O., B.S.-U. and R.T.; funding acquisition, D.R.-V., G.O., B.S.-U. and R.T. All authors have read and agreed to the published version of the manuscript.

Funding: The authors would like to thank the Vicerrectoría de Investigación, Universidad Nacional, Heredia, Costa Rica for the financial support for the publication of this manuscript.

Acknowledgments: The authors would like to express special thanks of gratitude to researchers of the CIDISAD and PROCESA laboratories, Heredia, Costa Rica, for their administrative and technical support for the development of this study.

Conflicts of Interest: The authors declare no conflict of interest.

\section{References}

1. Bellomo, R.; Kellum, J.A.; Ronco, C. Acute kidney injury. Lancet 2012, 380, 756-766. [CrossRef]

2. Bosch, X.; Poch, E.; Grau, J.M. Rhabdomyolysis and Acute Kidney Injury. N. Engl. J. Med. 2009, 361, 62-72. [CrossRef] [PubMed]

3. Gameiro, J.; Agapito Fonseca, J.; Jorge, S.; Lopes, J.A. Acute Kidney Injury Definition and Diagnosis: A Narrative Review. J. Clin. Med. 2018, 7, 307. [CrossRef] [PubMed]

4. Ronco, C.; Kellum, J.A.; Haase, M. Subclinical AKI is still AKI. Crit. Care 2012, 16, 313. [CrossRef]

5. Rojas-Valverde, D.; Sánchez-Ureña, B.; Crowe, J.; Timón, R.; Olcina, G.J. Exertional Rhabdomyolysis and Acute Kidney Injury in Endurance Sports: A Systematic Review. Eur. J. Sport Sci. 2020, 1-14. [CrossRef]

6. Rojas-Valverde, D.; Sánchez-Ureña, B.; Pino-Ortega, J.; Gómez-Carmona, C.; Gutiérrez-Vargas, R.; Timón, R.; Olcina, G. External Workload Indicators of Muscle and Kidney Mechanical Injury in Endurance Trail Running. Int. J. Environ. Res. Public Health 2019, 16, 3909. [CrossRef]

7. Belli, T.; Macedo, D.V.; de Araújo, G.G.; dos Reis, I.G.M.; Scariot, P.P.M.; Lazarim, F.L.; Nunes, L.A.S.; Brenzikofer, R.; Gobatto, C.A. Mountain Ultramarathon Induces Early Increases of Muscle Damage, Inflammation, and Risk for Acute Renal Injury. Front. Physiol. 2018, 9, 1368. [CrossRef] [PubMed] 
8. Hoffman, M.D.; Ingwerson, J.L.; Rogers, I.R.; Hew-Butler, T.; Stuempfle, K.J. Increasing Creatine Kinase Concentrations at the 161-km Western States Endurance Run. Wilderness Environ. Med. 2012, 23, 56-60. [CrossRef] [PubMed]

9. Hodgson, L.E.; Walter, E.; Venn, R.M.; Galloway, R.; Pitsiladis, Y.; Sardat, F.; Forni, L.G. Acute kidney injury associated with endurance events-Is it a cause for concern? A systematic review. BMJ Open Sport Exerc. Med. 2017, 3, e000093. [CrossRef]

10. Rojas-Valverde, D.; Olcina, G.; Gutiérrez-Vargas, R.; Crowe, J. Heat Strain, External Workload, and Chronic Kidney Disease in Tropical Settings: Are Endurance Athletes Exposed? Front. Physiol. 2019, 10, 1403. [CrossRef]

11. Wołyniec, W.; Kasprowicz, K.; Giebułtowicz, J.; Korytowska, N.; Zorena, K.; Bartoszewicz, M.; Tkachenko, P.R.; Renke, M.; Ratkowski, W. Changes in Water Soluble Uremic Toxins and Urinary Acute Kidney Injury Biomarkers after 10- and 100-km Runs. Int. J. Environ. Res. Public Health 2019, 16, 4153. [CrossRef]

12. Chawla, L.S.; Eggers, P.W.; Star, R.A.; Kimmel, P.L. Acute Kidney Injury and Chronic Kidney Disease as Interconnected Syndromes. N. Engl. J. Med. 2014, 371, 58-66. [CrossRef]

13. Thakar, C.V.; Christianson, A.; Himmelfarb, J.; Leonard, A.C. Acute Kidney Injury Episodes and Chronic Kidney Disease Risk in Diabetes Mellitus. Clin. J. Am. Soc. Nephrol. 2011, 6, 2567-2572. [CrossRef]

14. Scheer, V. Severe Kidney Injury after a 110-km Trail Race. Cureus 2020, 12, e7814.

15. McCullough, P.A.; Shaw, A.D.; Haase, M.; Bouchard, J.; Waikar, S.S.; Siew, E.D.; Murray, P.T.; Mehta, R.L.; Ronco, C. Diagnosis of Acute Kidney Injury Using Functional and Injury Biomarkers: Workgroup Statements from the Tenth Acute Dialysis Quality Initiative Consensus Conference. In ADQI Consensus on AKI Biomarkers and Cardiorenal Syndromes; McCullough, P.A., Kellum, J.A., Mehta, R.L., Murray, P.T., Ronco, C., Eds.; KARGER: Basel, Switzerland, 2013; pp. 13-29. Available online: https://www.karger.com/Article/FullText/349963 (accessed on 25 April 2020).

16. Devarajan, P. Emerging urinary biomarkers in the diagnosis of acute kidney injury. Expert Opin. Med. Diagn. 2008, 2, 387-398. [CrossRef]

17. Devarajan, P. Biomarkers for the early detection of acute kidney injury. Curr. Opin. Pediatr. 2011, 23, $194-200$. [CrossRef] [PubMed]

18. Gameiro, J.; Lopes, J.A. Complete blood count in acute kidney injury prediction: A narrative review. Ann. Intensive Care 2019, 9, 87. [CrossRef] [PubMed]

19. Lopes, J.A.; Jorge, S. The RIFLE and AKIN classifications for acute kidney injury: A critical and comprehensive review. Clin. Kidney J. 2013, 6, 8-14. [CrossRef]

20. Soto, K.; Coelho, S.; Rodrigues, B.; Martins, H.; Frade, F.; Lopes, S.; Luis, C.; Ana Luisa, P.; Prasad, D. Cystatin $\mathrm{C}$ as a marker of acute kidney injury in the emergency department. Clin. J. Am. Soc. Nephrol. 2010, 5, 1745-1754. [CrossRef]

21. Watson, D.; Yang, J.Y.C.; Sarwal, R.D.; Sigdel, T.K.; Liberto, J.; Damm, I.; Louie, V.; Sigdel, S.; Livingstone, D.; Soh, K.; et al. A Novel Multi-Biomarker Assay for Non-Invasive Quantitative Monitoring of Kidney Injury. J. Clin. Med. 2019, 8, 499. [CrossRef]

22. Shephard, R.J. Exercise proteinuria and hematuria: Current knowledge and future directions. J. Sports Med. Phys. Fit. 2016, 56, 1060-1076.

23. Wołyniec, W.; Kasprowicz, K.; Rita-Tkachenko, P.; Renke, M.; Ratkowski, W. Biochemical Markers of Renal Hypoperfusion, Hemoconcentration, and Proteinuria after Extreme Physical Exercise. Medicina 2019, 55, 154. [CrossRef]

24. Jouffroy, R.; Lebreton, X.; Mansencal, N.; Anglicheau, D. Acute kidney injury during an ultra-distance race. PLoS ONE 2019, 14, e0222544. [CrossRef] [PubMed]

25. Hoffman, M.D.; Stuempfle, K.J.; Fogard, K.; Hew-Butler, T.; Winger, J.; Weiss, R.H. Urine dipstick analysis for identification of runners susceptible to acute kidney injury following an ultramarathon. J. Sports Sci. 2013, 31, 20-31. [CrossRef] [PubMed]

26. Vuljanić, D.; Dojder, A.; Špoljarić, V.; Saračević, A.; Dukić, L.; Leniček-Krleža, J.; Tanasković, J.V.; Maradin, I.; Grzunov, A.; Vogrinc, Z.; et al. Analytical verification of 12 most commonly used urine dipsticks in Croatia: Comparability, repeatability and accuracy. Biochem. Med. 2019, 29, 123-132. [CrossRef]

27. Wołyniec, W.; Ratkowski, W.; Kasprowicz, K.; Małgorzewicz, S.; Aleksandrowicz, E.; Zdrojewski, T.; Wierucki, L.; Puch-Walczak, A.; Żmijewski, P.; Renke, M. Factors influencing post-exercise proteinuria after marathon and ultramarathon races. Biol. Sport 2020, 37, 33-40. [CrossRef] 
28. Sato, Y.; Roncal-Jimenez, C.A.; Andres-Hernando, A.; Jensen, T.; Tolan, D.R.; Sanchez-Lozada, L.G.; Newman, L.S.; Butler-Dawson, J.; Sorensen, C.; Glaser, J.; et al. Increase of core temperature affected the progression of kidney injury by repeated heat stress exposure. Am. J. Physiol. Ren. Physiol. 2019, 317, F1111-F1121. [CrossRef]

29. Schlader, Z.J.; Hostler, D.; Parker, M.D.; Pryor, R.R.; Lohr, J.W.; Johnson, B.D.; Chapman, C.L. The Potential for Renal Injury Elicited by Physical Work in the Heat. Nutrients 2019, 11, 2087. [CrossRef]

30. Wyness, S.P.; Hunsaker, J.J.H.; Snow, T.M.; Genzen, J.R. Evaluation and analytical validation of a handheld digital refractometer for urine specific gravity measurement. Pract. Lab. Med. 2016, 5, 65-74. [CrossRef] [PubMed]

31. Casa, D.J.; Armstrong, L.E.; Hillman, S.K.; Montain, S.J.; Reiff, R.V.; Rich, B.S.E.; Roberts, W.O.; Stone, J.A. National Athletic Trainers' Association Position Statement: Fluid Replacement for Athletes. J. Athl. Train. 2000, 35, 212-224. [PubMed]

32. Cohen, J. Statistical Power Analysis for the Behavioral Sciences, 2nd ed.; Hillsdale, N.J., Ed.; Academic Press: Cambridge, MA, USA, 1988.

33. Bongers, C.C.; Alsady, M.; Nijenhuis, T.; Tulp, A.D.; Eijsvogels, T.M.; Deen, P.M.; Hopman, M.T. Impact of acute versus prolonged exercise and dehydration on kidney function and injury. Physiol. Rep. 2018, 6, e13734. [CrossRef] [PubMed]

34. Hansson, E.; Glaser, J.; Weiss, I.; Ekström, U.; Apelqvist, J.; Hogstedt, C.; Peraza, S.; Lucas, R.; Jakobsson, K.; Wesseling, C.; et al. Workload and cross-harvest kidney injury in a Nicaraguan sugarcane worker cohort. Occup. Environ. Med. 2019, 76, 818-826. [CrossRef] [PubMed]

35. Giovanelli, N.; Taboga, P.; Rejc, E.; Šimunič, B.; Antonutto, G.; Lazzer, S. Effects of an Uphill Marathon on Running Mechanics and Lower-Limb Muscle Fatigue. Int. J. Sports Physiol. Perform. 2016, 11, 522-529. [CrossRef] [PubMed]

36. Vernillo, G.; Giandolini, M.; Edwards, W.B.; Morin, J.B.; Samozino, P.; Horvais, N.; Millet, G.Y. Biomechanics and Physiology of Uphill and Downhill Running. Sports Med. 2017, 47, 615-629. [CrossRef]

37. Carroll, M.F.; Temte, J.L. Proteinuria in adults: A diagnostic approach. Am. Fam. Physician 2000, 62, 1333-1340.

38. Filha RD, S.; Pinheiro SV, B.; Macedo e Cordeiro, T.; Feracin, V.; Vieira EL, M.; Miranda, A.S.; Simões e Silva, A.C. Evidence for a role of angiotensin converting enzyme 2 in proteinuria of idiopathic nephrotic syndrome. Biosci. Rep. 2019, 39. [CrossRef]

39. Akiboye, R.D.; Sharma, D.M. Haematuria in Sport: A Review. Eur. Urol. Focus 2019, 5, 912-916. [CrossRef]

40. Banfi, G.; Colombini, A.; Lombardi, G.; Lubkowska, A. Metabolic markers in sports medicine. Adv. Clin. Chem. 2012, 56, 1-54.

41. De Paz, J.A.; Villa, J.G.; Lopez, P.; Gonzalez-Gallego, J. Effects of long-distance running on serum bilirubin. Med. Sci. Sports Exerc. 1995, 27, 1590-1594. [CrossRef]

42. Shin, K.-A.; Park, K.D.; Ahn, J.; Park, Y.; Kim, Y.-J. Comparison of Changes in Biochemical Markers for Skeletal Muscles, Hepatic Metabolism, and Renal Function after Three Types of Long-distance Running. Medicine 2016, 95, e3657. [CrossRef]

43. Lippi, G.; Sanchis-Gomar, F. Epidemiological, biological and clinical update on exercise-induced hemolysis. Ann. Transl. Med. 2019, 7, 270. [CrossRef] [PubMed]

44. Gutiérrez-Vargas, R.; Martín-Rodríguez, S.; Sánchez-Ureña, B.; Rodríguez-Montero, A.; Salas-Cabrera, J.; Gutiérrez-Vargas, J.C. Biochemical and Muscle Mechanical Postmarathon Changes in Hot and Humid Conditions. J. Strength Cond. Res. 2018, 1. [CrossRef] [PubMed]

45. Junglee, N.A.; Di Felice, U.; Dolci, A.; Fortes, M.B.; Jibani, M.M.; Lemmey, A.B.; Walsh, N.P.; Macdonald, J.H. Exercising in a hot environment with muscle damage: Effects on acute kidney injury biomarkers and kidney function. Am. J. Physiol. Renal Physiol. 2013, 305, F813-F820. [CrossRef] [PubMed]

Publisher's Note: MDPI stays neutral with regard to jurisdictional claims in published maps and institutional affiliations.

(C) 2020 by the authors. Licensee MDPI, Basel, Switzerland. This article is an open access article distributed under the terms and conditions of the Creative Commons Attribution (CC BY) license (http://creativecommons.org/licenses/by/4.0/). 